2 High Intensity Focused Ultrasound Assisted Tryptic Digestion and

\title{
Selected MS/MS Ion Monitoring Mass Spectrometry
}

4

Mónica Carrera ${ }^{1, *}$, Benito Cañas ${ }^{2}$, Daniel López-Ferrer ${ }^{3}$, Carmen Piñeiro ${ }^{1}$, Jesús Vázquez ${ }^{3}$, José M. Gallardo ${ }^{1}$

7

$8{ }^{1}$ Marine Research Institute (IIM), CSIC, Vigo, Pontevedra, Spain.

$9{ }^{2}$ Complutense University of Madrid (UCM), Madrid, Spain.

$10{ }^{3}$ Severo Ochoa Molecular Biology Centre (CBMSO), CSIC, Madrid, Spain.

11

AUTHOR E-MAIL ADDRESS: mcarrera@iim.csic.es

13

TITLE RUNNING HEAD: Fast monitoring of peptide biomarkers by HIFU and SMIM

15

* CORRESPONDING AUTHOR: Dr. Mónica Carrera

17 Marine Research Institute (IIM), Spanish National Research Council (CSIC). Eduardo

18 Cabello 6, E-36208 Vigo, Pontevedra, Spain. Phone: +34 986 231930. Fax: +34 986292762. 


\section{ABSTRACT}

2

3

A new strategy for the fast monitoring of peptide biomarkers is described. It is based

4 on the use of accelerated in-solution trypsin digestions under an ultrasonic field provided by

5 High-Intensity Focused Ultrasound (HIFU) and the monitoring of several peptides by

6 Selected MS/MS Ion Monitoring (SMIM) in a linear ion trap (LIT) mass spectrometer. The

7 performance of the method was established for the unequivocal identification of all

8 commercial fish species belonging to the Merlucciidae family. Using a particular combination

9 of only eleven peptides, resulting from the HIFU-assisted tryptic digestion of the thermostable

10 proteins parvalbumins (PRVBs), the workflow allowed the unequivocal identification of these

11 closely related fish species in any seafood product, including processed and precooked

12 products, in less than $2 \mathrm{~h}$. The present strategy constitutes the fastest method for peptide

13 biomarker monitoring. Its application for food quality control provides to the authorities an

14 effective and rapid method of food authentication and traceability to guarantee the quality and

15 safety to the consumers.

KEYWORDS: mass spectrometry, biomarker, selected MS/MS ion monitoring (SMIM),

21 high-intensity focused ultrasound (HIFU), proteomics, parvalbumin, fish, food safety. 


\section{INTRODUCTION}

Fast monitoring of biomarkers is essential to achieve a rapid response and to take a

3 precise decision in diverse life fields. It is crucial in clinical diagnosis, therapeutic

4 supervision, environmental protection and food quality control among others ${ }^{1,2}$. Currently,

5 the most commonly used approach for the monitoring of peptide/protein biomarkers is based

6 on immunoassays, mainly using ELISA and array techniques ${ }^{1}$. The advantages of these

7 methods are their high specificity and sensitivity. Apart of being time consuming, a flaw of

8 these techniques is that not always the right antibody is available for each biomarker, making

9 lengthy and expensive work necessary to extend the battery of specific antibodies for new

10 standardized and affordable assays. Therefore, the development of alternative and fast

11 methodologies having high reproducibility, sensitivity and specificity are necessary.

12 The emerging targeted mass spectrometry (MS)-based proteomics techniques can 13 constitute an excellent alternative methodology. When these selective and sensitive operating

14 methods are used, the MS analyzer is centered on analyzing only the compound of interest by

15 selected reaction monitoring (SRM) or multiple reaction monitoring (MRM) ${ }^{3,4}$. Monitoring

16 transitions (suitable pairs of precursor and fragment ion $\mathrm{m} / \mathrm{z}$ ), constitute a common assay to

17 identify and quantify biomarkers and by inference, the change in the corresponding biological

18 condition being studied. This setup provides high analytical reproducibility, a good signal-to-

19 noise $(\mathrm{S} / \mathrm{N})$ ratio, and an increased dynamic range ${ }^{4}$. The capability of triple quadrupole (TQ)

20 instruments to selectively isolate a precursor ion and the fragment ion(s) it produces under

21 collision induced dissociation (CID) is exploited for the experiments using SRM or MRM 22 scan modes ${ }^{5}$.

While SRM and MRM performed on a TQ are the most sensitive scanning modes

24 (low-attomolar) with a broad dynamic range (up to five orders of magnitude) ${ }^{6}$, their

25 optimization for a definite SRM/MRM assay is time-consuming. More importantly, using 
1 these scanning procedures, complete MS/MS spectra are not registered. The MS/MS spectrum

2 of a molecule is of paramount importance to confirm the structure of the compound detected.

3 To solve this problem, new routines, like the MRM-triggered MS/MS using hydrid

4 quadrupole/linear ion trap mass spectrometers, have been explored ${ }^{7}$. In such assays, when a

5 significant signal for a specific MRM transition is detected, the instrument switches the third

6 quadrupole automatically to the ion trap mode, collecting the full MS/MS spectrum.

7 Selected MS/MS Ion Monitoring (SMIM) in ion trap (IT) mass spectrometer is another

8 scanning mode that allows for a sensitive monitoring of specific molecules, producing

9 complete structural information ${ }^{8}$. The high scanning speed attainable in the IT allows for the

10 production of MS/MS spectra in a fraction of a second, registering the information given by

11 the complete spectra. High confident MS/MS spectra are recorded due to the possibility of an

12 averaging of the signal during acquisition. The utility of this operating mode has been

13 demonstrated in several previously published studies $^{8-10}$, where the possibility of a virtual

14 plotting of all the transitions produced has been discussed.

15 The main difficulty when LC-MS is used to monitor biomarkers arises from the 16 complexity of samples, which may result in false positives. Although the chromatographic

17 gradient time may be properly manipulated to avoid this, lowering the number of components

18 in the sample, when it is possible, may help to simplify the assays. Shorter analysis times are

19 needed when fewer components are present in the sample. Fast and easy protein fractionation

20 or purification steps conducted prior to LC-MS analysis, makes the analysis simpler and 21 faster $^{11}$.

22 Procedures to enhance the protease activity, such as the application of microwaves ${ }^{12}$, 23 high pressure ${ }^{13}$ or the energy produced by ultrasound ${ }^{14}$, can accelerate the time consuming 24 trypsin digestion. The application of only 1-2 minutes of High Intensity Focused Ultrasound 
1 (HIFU) to in-solution tryptic digestions has been reported to achieve an efficiency and

2 reproducibility similar to that obtained by traditional overnight protocols ${ }^{14-16}$. A new targeted MS-based strategy for the fast monitoring of peptide biomarkers based

4 on the combination of these methodologies described is proposed and has been applied to the 5 fast authentication of all commercial species from Merlucciidae family. It is based on: (a) the 6 purification of PRVBs by heat treatment (Time: 45min), (b) their accelerated tryptic digestion 7 using HIFU (Time: 2 min) and (c) the monitoring of eleven PRVB peptide biomarkers by 8 SMIM in a linear ion trap (LIT) mass spectrometer (Time: $60 \mathrm{~min}$ ). Each step was 9 individually adjusted to minimize the time of analysis. With this new and competitive 10 strategy, the unequivocal identification of these close-related fish species in any seafood 11 products, including processed and precooked, can be achieved in less than $2 \mathrm{~h}$. 


\section{EXPERIMENTAL SECTION}

2

\section{1. Reference species and commercial foodstuffs}

All the main commercial species from the Merlucciidae family were employed in this study: eleven different hake species, including two different subspecies from Merluccius australis and two grenadier subspecies belonging to the Macruronus novaezelandiae species (Table 1). Except for European hake, the specimens were frozen on board at $-30{ }^{\circ} \mathrm{C}$, with special care in keeping their morphological characteristics in good shape, and shipped by plane to the laboratory for the analyses. The weight of every specimen studied was in the range of 3-6 kg. At least 10 fish belonging to each different species were subjected to taxonomical study according to their anatomical and morphological features by an expert marine biologist, and by genetic identification using FINS at the Food Biochemistry Laboratory from the Marine Research Institute (Vigo, Pontevedra, Spain). Five correctly identified individuals for each of the species were considered as reference species. In addition, for the validation step using commercial real samples, a total of ten hake foodstuffs were included in the work (Table 1). All samples were analyzed in triplicate.

\section{Parvalbumin purification}

Sarcoplasmic protein extraction was carried out by homogenizing $5 \mathrm{~g}$ of white muscle in $10 \mathrm{~mL}$ of $10 \mathrm{mM}$ Tris-HCl buffer $\mathrm{pH} 7.2$, supplemented with $5 \mathrm{mM}$ PMFS, during $30 \mathrm{~s}$ in an Ultra-Turrax device (IKA-Werke, Staufen, Germany). In the case of battered precooked foodstuffs the casing was first removed. The sarcoplasmic protein extracts were then centrifuged at $40000 \mathrm{~g}$ for $20 \mathrm{~min}$ at $4{ }^{\circ} \mathrm{C}$ (J221-M centrifuge; Beckman, Palo Alto, CA). PRVBs were purified by taking advantage of their thermostability, heating the sarcoplasmic extracts at $70^{\circ} \mathrm{C}$ for $5 \mathrm{~min}^{10}$. After centrifugation at $40000 \mathrm{~g}$ for $20 \mathrm{~min}(\mathrm{~J} 221-\mathrm{M}$ centrifuge; 
1 Beckman, Palo Alto, CA), supernatants composed mainly by PRVBs were quantified by the

2 bicinchoninic acid (BCA) method (Sigma-Chemical Co., USA).

3

\section{3. Protein digestion using HIFU}

PRVB supernatants were subjected to HIFU-assisted trypsin digestion as previously

6 described $^{14}$. A total of $20 \mu \mathrm{g}$ of heated extract were subjected to in-solution digestion with 1

$7 \mu \mathrm{g}$ trypsin without adding urea, DTT or iodoacetamide (Promega, Madison, WI, USA)

8 applying simultaneously HIFU. A high-intensity ultrasonic probe of $1 \mathrm{~mm}$ probe tip (Dr.

9 Hielscher, Teltow, Germany) was set to $50 \%$ of amplitude and was used to perform the ultra-

10 fast digestion for $1 \mathrm{~min}$. Another $1 \mu \mathrm{g}$ of trypsin was added again to the sample and the HIFU

11 application was repeated for $1 \mathrm{~min}$.

\section{LC-MS/MS analysis}

Peptide digests were acidified and analyzed by LC-ESI-IT-MS/MS using a Surveyor

LC-system coupled to an LTQ LIT mass spectrometer (Thermo Fisher, San Jose, CA). The peptide separation $(1 \mu \mathrm{g})$ was performed on a $0.18 \mathrm{~mm}$ x $150 \mathrm{~mm}$ BioBasic-18 RP column

17 (ThermoHypersil-Keystone), using 0.5\% acetic acid in Milli-Q-water and in $80 \%$ ACN as mobile phases A and B, respectively. A 60 min linear gradient from 5 to $40 \% \mathrm{~B}$, at a flow rate of 1.5-1.7 $\mu \mathrm{L} / \mathrm{min}$ was used. ESI parameters were: spray voltage, $3.5 \mathrm{kV} ; \mathrm{N}_{2}$ flow, 10 arbitrary units; and capillary temperature, $200^{\circ} \mathrm{C}$. Peptides were analyzed in positive mode

21 from 400 to 1600 amu (3 $\mu$ scans), followed by four data-dependent MS/MS scans ( $3 \mu$ scans), using an isolation width of 3 amu and a normalized collision energy of $35 \%$. Fragmented masses were set in dynamic exclusion for $3 \mathrm{~min}$ after the second fragmentation event and singly charged ions were excluded from MS/MS analysis. 


\section{5. Selected MS/MS Ion Monitoring (SMIM)}

SMIM analysis was performed using a Surveyor LC-system coupled to an LTQ LIT mass spectrometer (Thermo Fisher, San Jose, CA), as described previously ${ }^{8}$ with minor modifications. The peptide separation $(1 \mu \mathrm{g})$ was performed on a $0.18 \mathrm{~mm} \mathrm{x} 150 \mathrm{~mm}$ BioBasic-18 RP column (ThermoHypersil-Keystone), using $0.5 \%$ acetic acid in water and in $80 \% \mathrm{ACN}$ as mobile phases A and B, respectively. A 45 min linear gradient from 5 to $40 \%$ $\mathrm{B}$, at a flow rate of 1.5-1.7 $\mu \mathrm{L} / \mathrm{min}$ was used. ESI parameters were as described previously. Peptides were detected in the positive ion mode using the $\mathrm{SMIM}^{8}$. For this method, the MS instrument was programmed to perform continuous MS/MS scans (5 $\mu$ scans) of doublycharged precursor ions from all candidate peptide biomarkers along the complete chromatographic separation. Normalized collision energy was set to $35 \%$ and a 3 amu mass window was used to fragment selected parent ions.

\section{Mass spectrometry data processing}

MS/MS spectra were searched using SEQUEST (Bioworks 3.1 package, Thermo Fisher), against the Teleostei UniProt/TrEMBL database (release 2010_12; 158.545 entries), which also included their respective decoy sequences. The following constraints were used for the searches: semi-tryptic cleavage with up to two missed cleavage sites and tolerances 1.8 Da for precursor ions and 0.8 Da for MS/MS fragments ions. The variable modifications allowed were methionine oxidation (Mox), carbamidomethylation of Cys $\left(\mathrm{C}^{*}\right)$ and acetylation of the N-terminus of the protein (N-Acyl). The database search results were subjected to statistical analysis with the PeptideProphet algorithm (v.4.4) ${ }^{20}$. The FDR was kept below $1 \%$.

The proteins identified in the original and heated sarcoplasmic extracts, were submitted to Ingenuity Pathway Analysis (IPA; Ingenuity Systems, CA). Only pathways 
1 scoring $-\log (\mathrm{p}$-value $) \geq 2$, which have $>99 \%$ confidence of not being generated by chance,

2 were selected.

3 For the SMIM mode, virtual chromatograms traces were plotted and optimized using

4 QualBrowser software (Thermo Fisher) to show the selected transitions for each parent ion.

5 In addition, MS/MS spectra collected in the SMIM mode were used to validate the peptide

6 identities using SEQUEST as is described before.

7

8

9

10

11

12

13

14

15

16

17

18

19

20

21

22

23

24

25 


\section{RESULTS AND DISCUSSION}

2

\section{1. Strategy for the fast monitoring of species-specific peptide biomarkers}

The strategy for the fast monitoring of peptide biomarkers proposed in this work is summarized in Figure 1. This strategy integrates three steps: (a) purification of thermostable proteins (PRVBs) by short heat treatment followed by centrifugation (Time: $45 \mathrm{~min}$ ), (b) insolution trypsin digestion accelerated using HIFU (Time: 2 min) and (c) monitoring of eleven species-specific PRVB peptide biomarkers by SMIM using a LIT mass spectrometer (Time: $60 \mathrm{~min})$. With this strategy, all relevant commercial fish species belonging to the Merlucciidae family can be unequivocally identified in any seafood product, including precooked, in less than $2 \mathrm{~h}$. The detailed results for each step and the validation of this new fast monitoring strategy using unknown hake commercial products are shown in the following sections.

\section{PRVB purification and enzymatic digestion accelerated by HIFU}

PRVBs, considered as the best protein biomarker for the authentication of Merluciidae species $^{10,21}$, were purified from the sarcoplasmic extracts taking advantage of their thermostability ${ }^{10}$. Figure S-1 in the Supplemental Data 1 (Supporting Information) shows a summary of the protein composition in the extracts before and after the treatment with heat $\left(70^{\circ} \mathrm{C}\right.$ for $\left.5 \mathrm{~min}\right)$. The complete list of proteins and peptides for both samples, identified by

LC-MS/MS and Sequest search after a conventional overnight trypsin digestion ${ }^{22}$, are presented in the Supplemental Data 2. Protein composition of the original sarcoplasmic extracts revealed more than 125 different proteins involved in 10 relevant functional pathways (Table S-1 in the Supplemental Data 1). After treatment with heat, the majority of identified peptides corresponded to PRVBs (77.87\%) (Figure S-1 in the Supplemental Data 1). These 
1 results demonstrated that the treatment with heat is a simple, fast and effective procedure to

2 purify and enrich the samples in only PRVBs.

Purified PRVBs were digested with trypsin using, either the conventional overnight

4 procedure, or the fast accelerated by HIFU. As reported previously ${ }^{14}$, HIFU assisted digestion

5 produced results comparable to those obtained by the conventional overnight incubation

6 methods, but in a fraction of time. Moreover, the absence of urea in the digestion buffer

7 prevented undesired peptide side reactions, such as carbamylation of N-termini and Lys

8 residues, which may occur when HIFU is applied in the presence of urea ${ }^{23,24}$.

9 The combination of a fast and easy protein purification procedure (Time: 45 min) with

10 the use of HIFU for the protein digestion (Time: 2 min), considerably simplified and reduced

11 the time needed for the sample preparation, reflected in the overall time needed for 12 monitoring.

14 3. Selection of the species-specific peptide biomarkers

The next step in the proposed strategy consisted in selecting the smaller number of

16 species-specific peptides, which must be monitored, to effectively identify all the species

17 from Merlucciidae family. Parvalbumins peptide sequences with a high inter-specific

18 variability, obtained after the extensive de novo sequencing of PRVBs previously published ${ }^{10}$,

19 were used for the purpose. Eleven tryptic peptides were selected in basis of the information

20 that their combined presence or absence could provide to confidently identify all of the

21 species under the study (Table 2). A BLAST search was performed using the UniProtKB

22 database to validate the uniqueness of the peptide sequences selected. Four of them were

23 present in only one specific species and can be considered as a canonical peptide for each of

24 these Merlucciidae species (S-MER794, S-MER612, S-MER721, S-MER973). The sequences

25 of the rest were shared by PRVBs from several Merlucciidae species or other organisms. 
1 However, their use following a specific and systematic combination avoids interferences and

2 allows for a correct discrimination of all the hake species under the study. Figure 2 shows the

3 flow diagram for the unambiguous systematic discrimination which can be achieved.

4 According to this scheme, the presence/absence of the peptide F-MER604 determines if any

5 member from Merlucciidae family is present in the sample. Discrimination between the

6 genera Merluccius spp. and Macruronus spp. can be achieved by the determination of

7 presence/absence of peptides G-MER517 and G-MAC524, respectively. Within the

8 Merluccius genus, the presence/absence of the peptide S-MER967 allows for the

9 classification of hake species in two groups according to their geographic distribution:

10 American hakes (M. hubbsi, M. gayi, M. australis polylepis, M. australis australis, M.

11 productus or $M$. bilinearis) or Euro-African hakes (M. merluccius, M. capensis, $M$.

12 senegalensis, M. polli or M. paradoxus). Finally, as can be seen in Figure 2, the combination

13 of the presence/absence of other eight peptides allows for the unambiguous identification of

14 any specific species from the Merlucciidae family.

\section{4. Fast identification of hake species using SMIM}

For each of the reference hake species, PRVBs peptide pools obtained from the accelerated tryptic digestions were subjected to SMIM analysis in a LIT mass spectrometer

19 focusing the MS/MS events on the corresponding precursor ions for the eleven peptides

20 selected. The selected $\mathrm{m} / \mathrm{z}$ value for each of precursor ion corresponded to the predominant 21 charge state, which was +2 for all of them (Table 2). Figure S-2 in the Supplemental Data 1 22 details the MS/MS spectra for each peptide. Once MS/MS spectra were recorded, virtual 23 chromatograms for all the different fragment ions could be obtained. For each of the peptide 24 markers, mass transitions were noted according to the criteria of sensitivity and selectivity. As 25 the peptide mixture used is not too complex, selectivity was not a matter of concern and the 
1 transitions chosen in every case was in accordance with the maximum intensity of the

2 fragments, which mostly corresponded to $y$-ions. Therefore, the combination of highly

3 sensitive transitions (precursor $m / z \rightarrow$ fragment $m / z$ ) (Table 2), together with the use of simple

4 peptide mixtures (coming mainly from PRVBs), made possible the representation of specific

5 transitions with a high signal-to-noise $(\mathrm{S} / \mathrm{N})$ ratio. Tracing these transitions for each peptide

6 biomarker, according to the flow diagram described in the Figure 2, made possible to identify

7 unequivocally all the reference hake species (Figure 3).

The results obtained matched precisely with those obtained by DNA-analysis.

9 However, the time needed for performing both techniques was extremely different. At least 24

$10 \mathrm{~h}$ were needed for a genetic identification by FINS, while only less than $2 \mathrm{~h}$ were necessary to

11 complete the identification following the proposed strategy. To our knowledge, this is the

12 fastest method to achieve the food species authentication.

\section{5. Application to commercial samples identification}

In order to validate this new strategy, ten commercial hake products were subjected to

16 analysis for their authentication. Table 1 summarizes the products that were tested, which had

17 been previously subjected to one or more processing treatments, even precooked. Two main

18 label categories were observed: labels with species declared (4 samples) and labels with no

19 declared species, which presented only a general commercial name (i.e. hake) (6 samples).

20 Results for the identification of the commercial samples using the designed strategy are

21 shown in the Table 3 and in the Figure S-3 in the Supplemental Data 1. Samples with

22 complete declared labelling were found to be mostly correct (CP1-CP4). However, some

23 products with no declared species were assigned to species belonging to the Macruronus

24 genus (CP8 and CP9). This genus presents a low commercial value and is not as valued by the

25 consumer $^{25}$. We have presented here a strategy that allows the fast detection of mislabelling 
1 practices in these fish products and moreover, this work also shown that the use of 2 thermostable proteins allow the application of this fast monitoring method to battered 3 precooked products (CP6-CP10).

4

5

6

7

8

9

10

11

12

13

14

15

16

17

18

19

20

21

22

23

24

25 


\section{CONCLUSIONS}

2 A new strategy for the fast monitoring of species-specific peptide biomarkers for

3 foodstuff authentication has been proposed. The principle it is based on the use of a fast

4 purification step of the target protein, the acceleration of in-solution protein digestion by

5 High-Intensity Focused Ultrasound (HIFU) and the monitoring of several peptides by

6 Selected ion MS/MS Monitoring mass spectrometry (SMIM) in a linear ion trap mass

7 spectrometer. The use of the SMIM mode of scanning allows for a more simple setting of the

8 procedures, giving the possibility of obtaining full MS/MS information necessary for the

9 validation of the structure of the component and allows the choice of the most adequate

10 transitions for each precursor ion, attending the criteria of sensitivity and selectivity. Thus, in

11 combination with a fast purification and digestion step of the target protein, the most sensitive

12 transitions may be considered for all the markers.

13 With this new strategy, all relevant commercial fish species belonging to the

14 Merlucciidae family present in any seafood product can be unequivocal identified in less than

$152 \mathrm{~h}$. The present strategy constitutes the fastest method for peptide biomarker monitoring by

16 targeted-proteomics described up to now, whose application in the food quality control area,

17 provide to the authorities an effective, competitive and rapid method of food authentication

18 and traceability that guarantee the quality and safety to the consumers. 


\section{REFERENCES}

2

3 (1) Zangar, R. C.; Daly, D. S.; White, A. M. Expert Rev. Proteomics 2006, 3, 37-44.

4 (2) Schubert-Ullrich, P.; Rudolf, J.; Ansari, P.; Galler, B.; Führer, M.; Molinelli, A.; Baumgartner, S. Anal. Bioanal. Chem. 2009, 395, 69-81.

6 (3) Gallien, S., Duriez, E., Domon, B. J. Mass Spectrom. 2011, 46, 298-312.

7 (4) Lange, V.; Picotti, P.; Domon, B.; Aebersold, R. Mol. Syst. Biol. 2008, 4, 1-14.

8 (5) Picotti, P.; Rinner, O.; Stallmach, R.; Dautel, F.; Farrah, T.; Domon, B.; Wenschuh, H.; Aebersold, R. Nat. Methods 2010, 7, 43-46.

10 (6) Stahl-Zeng, J.; Lange, V.; Ossola, R.; Eckhardt, K.; Krek, W.; Aebersold, R.; Domon, B. Mol. Cell Proteomics 2007, 6, 1809-1817.

(7) Unwin, R. D.; Griffiths, J. R.; Whetton, A. D. Nat. Protoc. 2009, 4, 870-877.

(8) Jorge, I.; Casas, E. M.; Villar, M.; Ortega-Pérez, I.; López-Ferrer, D.; Martínez-Ruiz,

(9) Carrera, M.; Cañas, B.; Piñeiro, C.; Vázquez, J.; Gallardo, J. M. J. Proteome Res. 2007, 6, 3070-3080.

(10) Carrera, M.; Cañas, B.; Vázquez, J.; Gallardo, J. M. J. Proteome Res. 2010, 9, 43934406.

(11) Cañas, B.; Piñeiro, C.; Calvo, E.; López-Ferrer, D.; Gallardo, J. M. J. Chromatogr. A 2007, 1153, 235-258.

(12) Sun, W.; Gao, S.; Wang, L.; Chen, Y.; Wu, S.; Wang X.; Zheng D.; Gao, Y. Mol. Cell. Proteomics 2006, 5, 769-776. 
1 (13) López-Ferrer, D.; Petritis, K.; Hixson, K. K.; Heibeck, T. H.; Moore, R. J.; Belov, M. E.; Camp, D. G. $2^{\text {nd }}$; Smith, R. D. J. Proteome Res. 2008, 7, 3276-3281.

3 (14) López-Ferrer, D.; Capelo, J. L.; Vázquez, J. J. Proteome Res. 2005, 4, 1569-1574.

4 (15) López-Ferrer, D.; Cañas, B.; Vázquez, J.; Lodeiro, C.; Rial-Otero, R.; Moura, I.; Capelo, J. L. Trends Anal. Chem. 2006, 25, 996-1005.

6 (16) Capelo, J. L.; Carreira, R.; Diniz, M.; Fernandes, L.; Galesio, M.; Lodeiro, C.; Santos, H. M.; Vale, G. Anal. Chim. Acta 2009, 650, 151-159.

8 (17) Civera, T. Vet. Res. Commun. 2003, 27, 481-489.

9 (18) Chapela, M. J.; Sánchez, A.; Suárez, M. I.; Pérez-Martín, R. I.; Sotelo, C. G. J. Agric.

(19) Rasmussen, R. S.; Morrissey, M. T. Compr. Rev. Food Sci. Food Saf. 2008, 7, 280-

(25) Lloris, D.; Matallanas, J.; Oliver, P. FAO Species Catalogue for Fishery Purposes No. 2. FAO 2005. 


\section{ACKNOWLEDGEMENTS}

2

Authors wish to express their gratitude to Mrs. Lorena Barros for her excellent

3 technical assistance and to Freiremar SA and CETMAR for their assistance in the collection

4 of the reference species used in this study. This work was supported by the Comisión

5 Interministerial de Ciencia y Tecnología (CICyT) (Project AGL2000-0440-P4-02).

6

7

8

9

10

11

12

13

14

15

16

17

18

19

20

21

22

23

24

25 


\section{FIGURE CAPTIONS}

2 Figure 1: Analytical scheme for the fast monitoring of the species-specific peptide 3 biomarkers proposed in this work.

4

5 Figure 2: Flow diagram for a systematic discrimination of Merlucciidae species using only

6 eleven specific tryptic peptides from PRVBs. Y denotes the presence and $\mathrm{N}$ the absence of a 7 particular peptide.

8

9 Figure 3: Reference SMIM traces for each of Merlucciidae species, plotting the 10 corresponding canonical transition for each of PRVB tryptic peptide biomarker.

11

12

13

14

15

16

17

18

19

20

21

22

23

24 
1 Table 1: Reference species and commercial foodstuffs from the Merlucciidae family

2 considered in the study.

Reference species

\begin{tabular}{|c|c|c|}
\hline Species/Subspecies & Common Name & Origin \\
\hline M. merluccius & European hake & Spanish coasts \\
\hline M. capensis & Cape hake & South Africa \\
\hline M. senegalensis & Senegalense hake & Northwest Africa \\
\hline M. polli & Benguela hake & Northwest Africa \\
\hline M. paradoxus & Deep-water Cape hake & South Africa \\
\hline M. hubbsi & Patagonian hake & South America \\
\hline M. gayi & Peruvian or Chilean hake & South America \\
\hline M. australis polylepis & Austral hake & South America \\
\hline M. australis australis & Austral hake & New Zealand coasts \\
\hline M. productus & Pacific hake & North America \\
\hline M. bilinearis & Silver hake & North America \\
\hline Ma. nov. nov. & Blue grenadier & New Zealand coasts \\
\hline Ma. nov. magellanicus & Patagonian grenadier & South America \\
\hline
\end{tabular}

Commercial products

\begin{tabular}{|c|c|c|}
\hline Code & Product Presentation & Declared Species \\
\hline $\mathrm{CP} 1$ & Raw fillets frozen & M. capensis or M. paradoxus \\
\hline $\mathrm{CP} 2$ & Raw center cuts frozen & M. autralis \\
\hline CP3 & Raw loins frozen & M. capensis or M. paradoxus \\
\hline $\mathrm{CP} 4$ & Raw center cuts frozen & M. capensis or M. paradoxus \\
\hline CP5 & Raw center cuts frozen & Hake unidentified \\
\hline CP6 & Battered precooked sticks frozen & Hake unidentified \\
\hline CP7 & Battered precooked sticks frozen & Hake unidentified \\
\hline CP8 & Battered precooked sticks frozen & Hake unidentified \\
\hline CP9 & Battered precooked sticks frozen & Hake unidentified \\
\hline CP10 & Battered precooked fillets frozen & Hake unidentified \\
\hline
\end{tabular}

3 M. (Merluccius genus); Ma. nov. (Macruronus novaezelandiae). 
1 Table 2. Peptide biomarkers and specific transitions for the identification of all species from Merlucciidae family.

2

\begin{tabular}{|c|c|c|c|c|c|c|c|c|c|c|c|c|c|c|c|c|}
\hline $\begin{array}{l}\text { Biomarker } \\
\text { code }\end{array}$ & Peptide Sequence & $\begin{array}{c}\text { SMIM Transition } \\
m / z \text { precursor ion }(z) \rightarrow m / z \text { fragment ion }\end{array}$ & $\begin{array}{c}\text { Retention } \\
\text { time (min) }\end{array}$ & S1 & S2 & S3 & S4 & S5 & S6 & S7 & S8 & S9 & S10 & S11 & S12 & $\begin{array}{c}\text { Cross-reaction with proteins } \\
\text { from other organisms by } \\
\text { BLAST }\end{array}$ \\
\hline F-MER604 & LFLQVFSAGAR & $604.84(2+) \rightarrow 948.52\left(\mathrm{y}^{\prime \prime}{ }_{9}^{+}\right)$ & 23.00 & & & & & & & & & & & & & - \\
\hline G-MER517 & VFGIIDQDK & $517.78(2+) \rightarrow 788.41\left(\mathrm{y}_{7}^{+}\right)$ & 20.00 & & & & & & & & & & & & & - \\
\hline G-MAC524 & VFAIIDQDK & $524.79(2+) \rightarrow 802.43\left(\mathrm{y}_{7}{ }^{+}\right)$ & 20.00 & & & & & & & & & & & & & Xenopus laevis, Xenopus tropicalis \\
\hline S-MER967 & AGDSDGDGAIGVDEFAVLVK & $967.97(2+) \rightarrow 1189.68\left(\mathrm{y}_{11}{ }^{+}\right)$ & 21.50 & & & & & & & & & & & & & - \\
\hline S-MER794 & (N-Acyl)AFSGILADADIAAALK & $794.93(2+) \rightarrow 1187.59\left(b_{12}\right)$ & 25.00 & & & & & & & & & & & & & - \\
\hline S-MER612 & IGVDEFTAMLK & $612.32(2+) \rightarrow 954.46\left(\mathrm{y}_{8}{ }^{+}\right)$ & 22.50 & & & & & & & & & & & & & - \\
\hline S-MER736 & AEGTFTHGEFFTK & $736.35(2+) \rightarrow 966.46\left(\mathrm{y}_{8}{ }^{+}\right)$ & 23.00 & & & & & & & & & & & & & - \\
\hline S-MER721 & AEGTFTHGVFFTK & $721.36(2+) \rightarrow 936.49\left(\mathrm{y}_{8}{ }^{+}\right)$ & 23.50 & & & & & & & & & & & & & - \\
\hline S-MER590 & IGVDEFAAMVK & $590.31(2+) \rightarrow 910.43\left(\mathrm{y}_{8}{ }^{+}\right)$ & 22.50 & & & & & & & & & & & & & Trachurus japonicus and others ${ }^{a}$ \\
\hline S-MER973 & AGDSDGDGAIGVDEWAALVK & $973.46(2+) \rightarrow 1087.57\left(\mathrm{y}{ }_{10}{ }^{+}\right)$ & 23.00 & & & & & & & & & & & & & - \\
\hline S-MER987 & AGDSDGDGAIGVDEWAVLVK & $987.48(2+) \rightarrow 1115.61\left(\mathrm{y}{ }_{10}^{+}\right)$ & 22.50 & & & & & & & & & & & & & Gadus morhua \\
\hline
\end{tabular}

$m / z$ (mass/charge).

(घ) Denotes the presence of a peptide biomarker and ( $\square$ ) the absence.

S1 (Merluccius merluccius), S2 (M. capensis), S3 (M. senegalensis), S4 (M. polli), S5 (M. paradoxus), S6 (M. hubbsi), S7 (M. gayi), S8 (M. australis polylepis),

S9 (M. australis australis), S10 (M. productus), S11(M. bilinearis), S12(Macruronus spp.).

(') Sparus aurata, Fundulus grandis, Fundulus similis, Fundulus heteroclitus, Hypophthalmichthys nobilis, Paralichthys olivaceus, Theragra chalcogramma. 
1 Table 3: Results of the SMIM assay of commercial hake products.

\begin{tabular}{|c|c|c|}
\hline Product & Declared species & $\begin{array}{c}\text { Species identified by HIFU }+ \text { SMIM } \\
\text { Time: }<2 \mathrm{~h}(*)\end{array}$ \\
\hline CP1 & M. capensis or M. paradoxus & M. paradoxus \\
\hline $\mathrm{CP} 2$ & M. australis & M. australis polylepis \\
\hline $\mathrm{CP} 3$ & M. capensis or M. paradoxus & M. paradoxus \\
\hline $\mathrm{CP} 4$ & M. capensis or M. paradoxus & M. capensis \\
\hline CP5 & Hake unidentified & M. paradoxus \\
\hline CP6 & Hake unidentified & M. productus \\
\hline $\mathrm{CP} 7$ & Hake unidentified & M. paradoxus \\
\hline CP8 & Hake unidentified & Macruronus spp. \\
\hline CP9 & Hake unidentified & Macruronus spp. \\
\hline $\mathrm{CP} 10$ & Hake unidentified & M. paradoxus \\
\hline M. $(M e$ & $i s$ genus). ${ }^{*}$ These results $\mathrm{W}$ & lidated by genetic after $24 \mathrm{~h}$ of an \\
\hline
\end{tabular}


$1 \quad$ Figure 1

2

3

4

5

6

7

8

9

10

11

12

13

14 Time: $60 \mathrm{~min}$

Time: 2 min
SAMPLE PROBLEM

Fresh products, frozen, processed or precooked

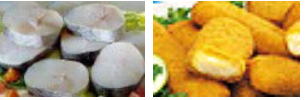

SARCOPLASMIC PROTEIN EXTRACTION

Time: 45 min PURIFICATION OF THERMOSTABLE PROTEINS (PARVALBUMINS)
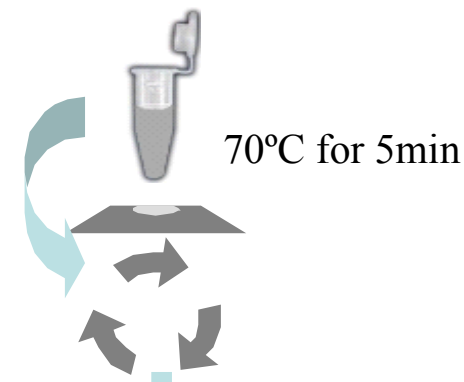

ACCELERATED TRYPTIC DIGESTION BY HIFU

15

16

17

18

19

20

21

22

23

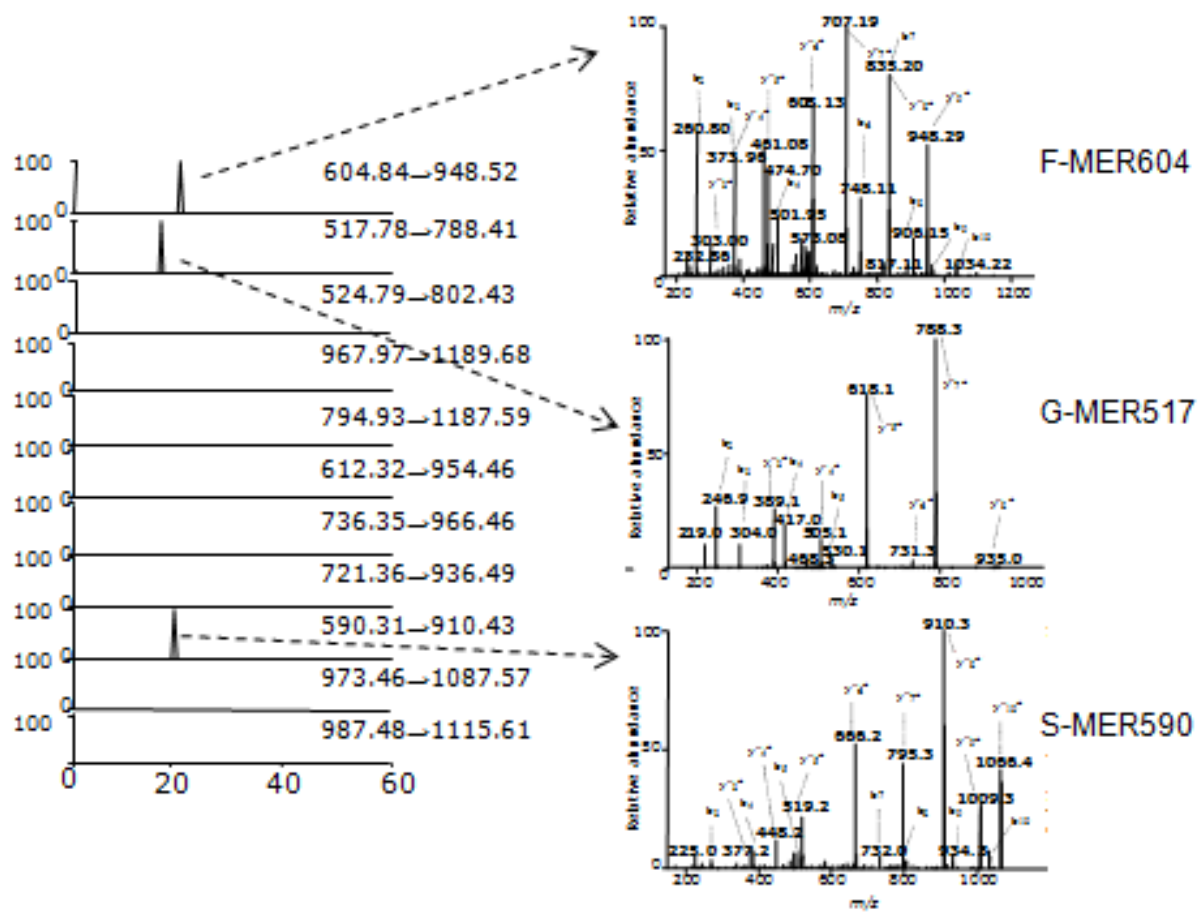

25

SPECIES IDENTIFICATION 


\section{Figure 2}

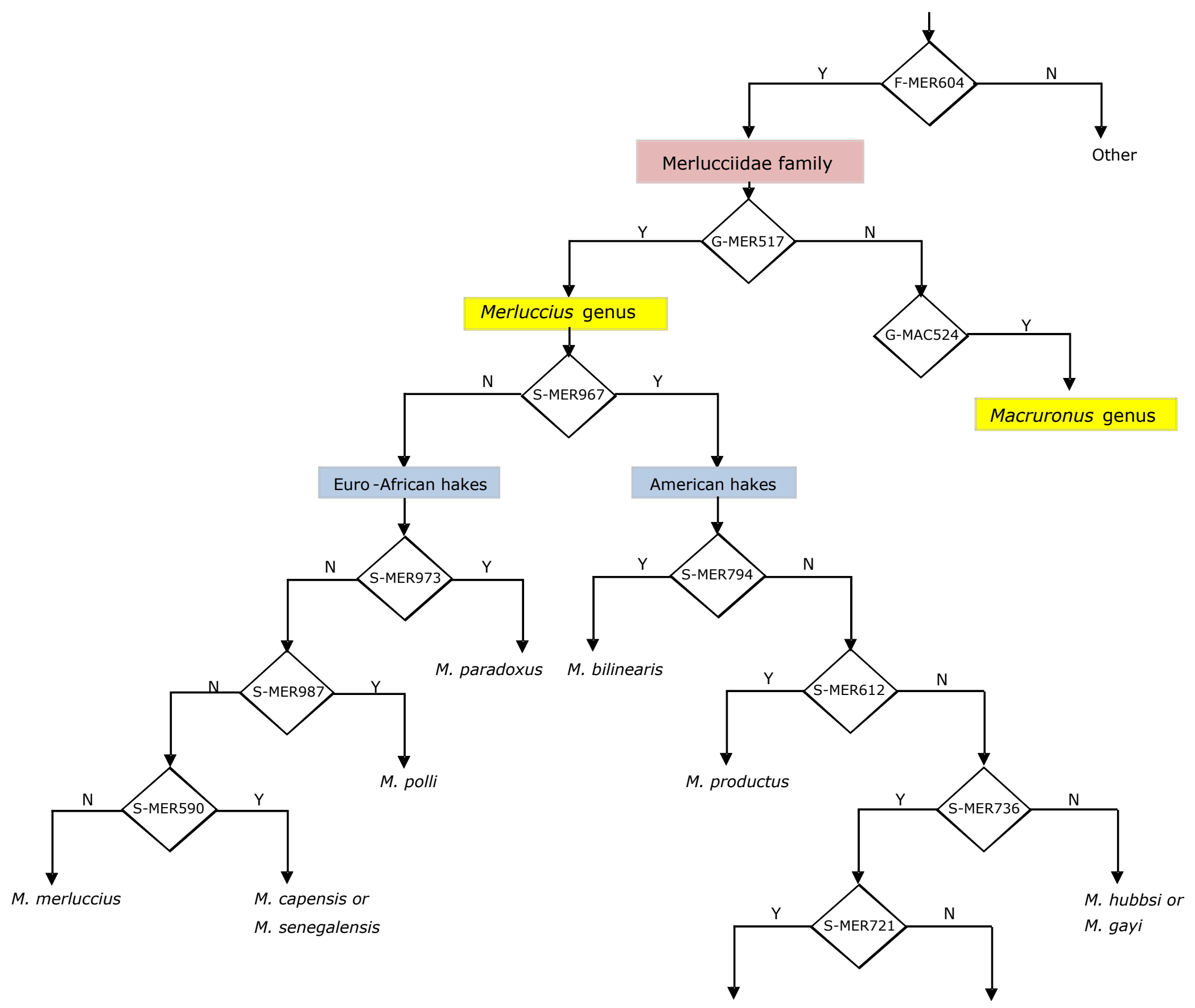




\section{$1 \quad$ Figure 3}

2

3

4

5

6

7

8

9

10

11

12

13

14

15

16

17

18

19

20

21

22

23

24 a) M. merluccius

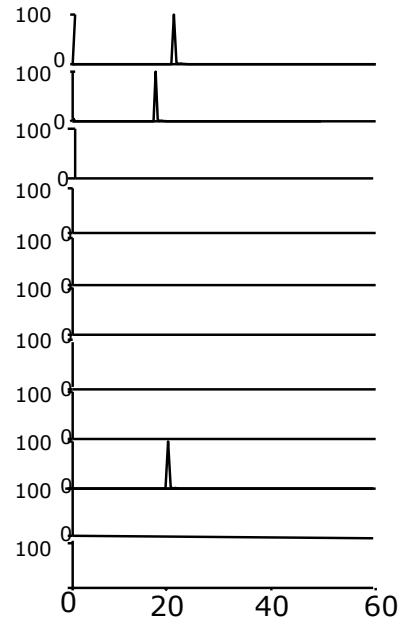

e) M. paradoxus

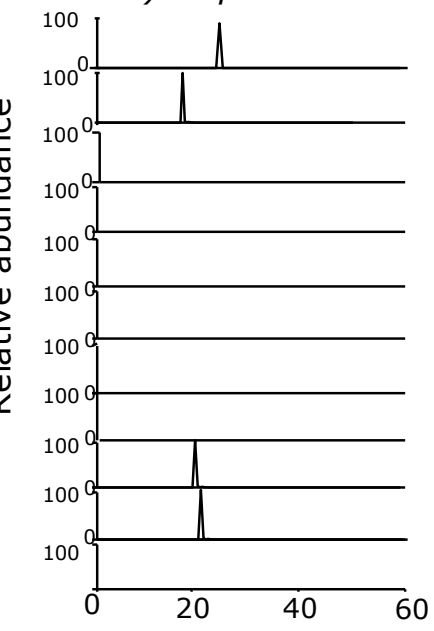

i) M. australis australis

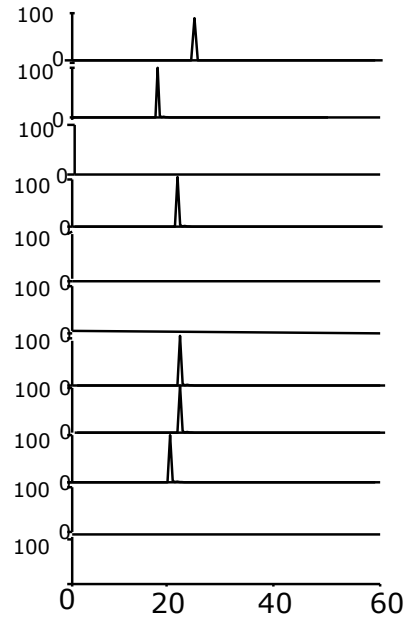

b) M. capensis

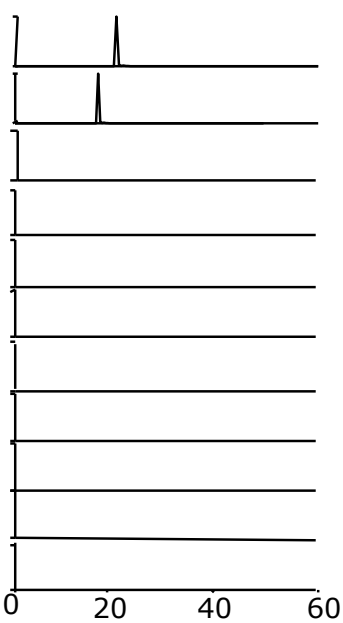

f) M. hubbsi
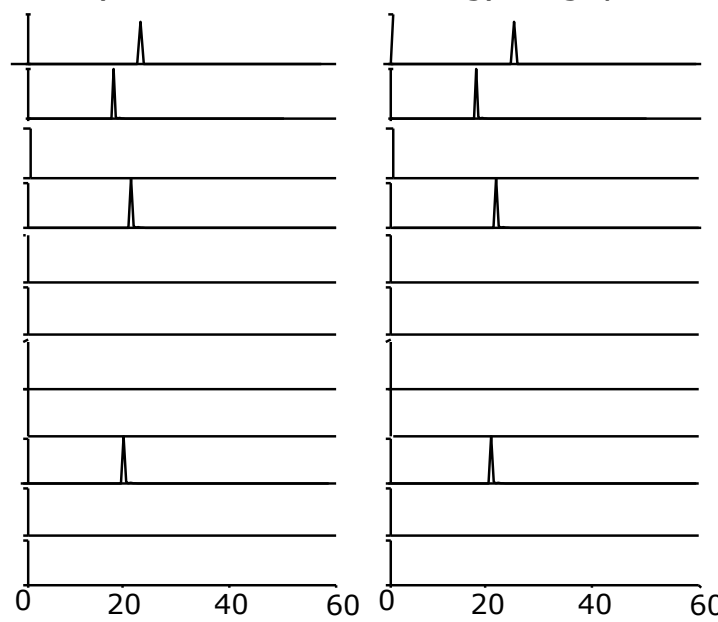

k) M. bilinearis
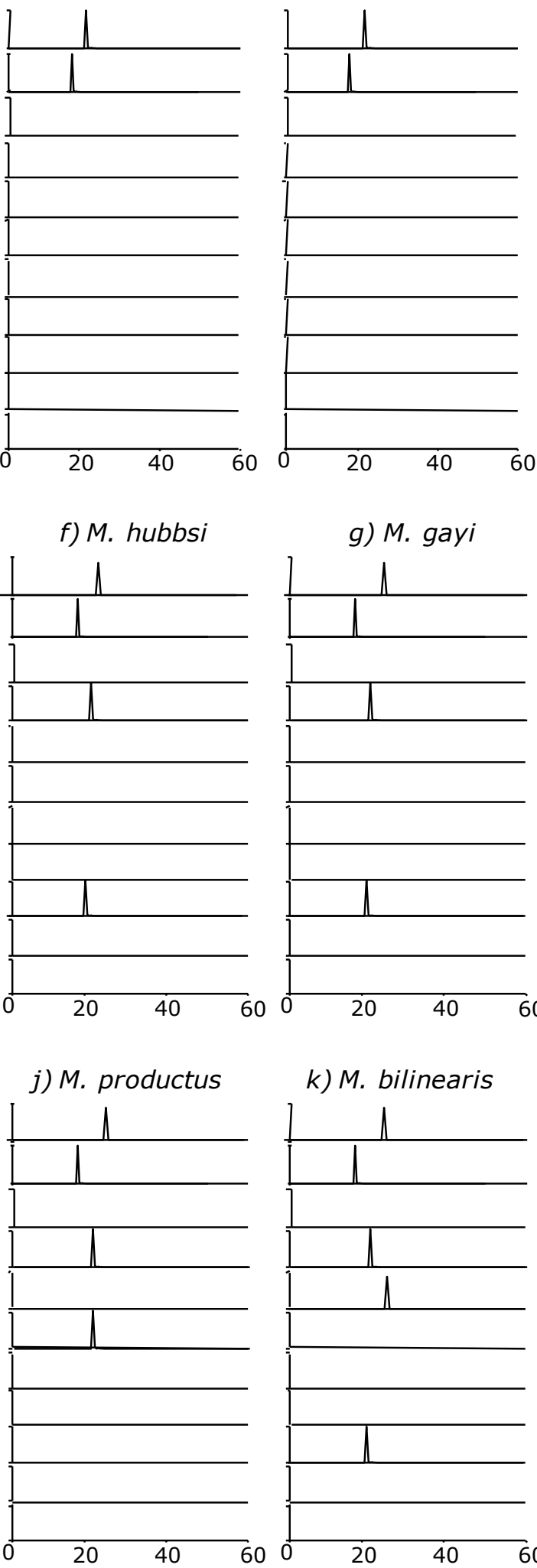

g) M. gayi

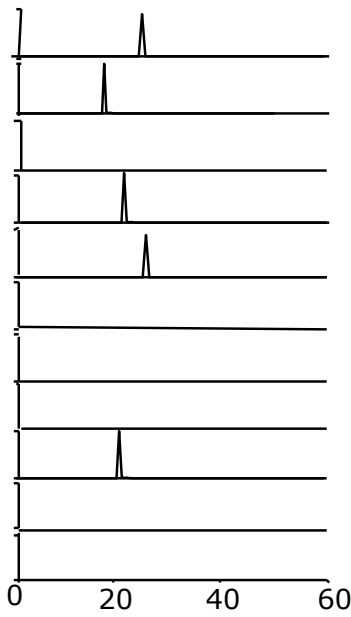

c) M. senegalensis h) M. australis polylepis

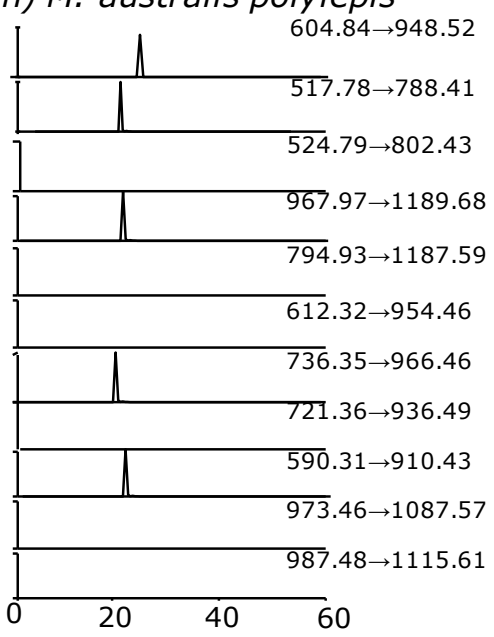

1) Macruronus spp.

$604.84 \rightarrow 948.52$ $517.78 \rightarrow 788.41$ $524.79 \rightarrow 802.43$ $967.97 \rightarrow 1189.68$

$794.93 \rightarrow 1187.59$ $612.32 \rightarrow 954.46$ $736.35 \rightarrow 966.46$ $721.36 \rightarrow 936.49$ $590.31 \rightarrow 910.43$ $973.46 \rightarrow 1087.57$ $987.48 \rightarrow 1115.61$ 60
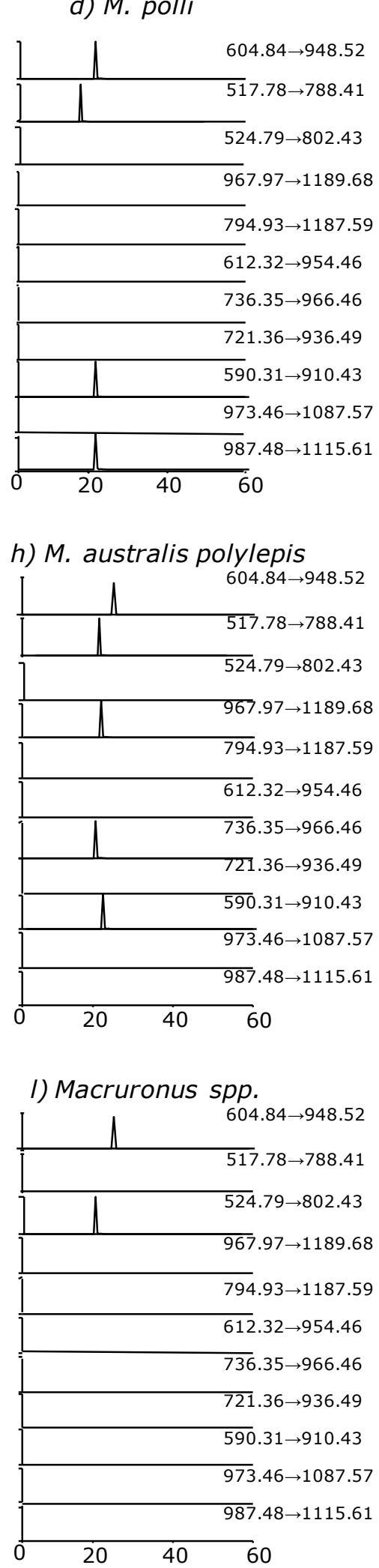

Time (min) 
1 for TOC only:

2

3

4

5

6

7

8

9

10

11

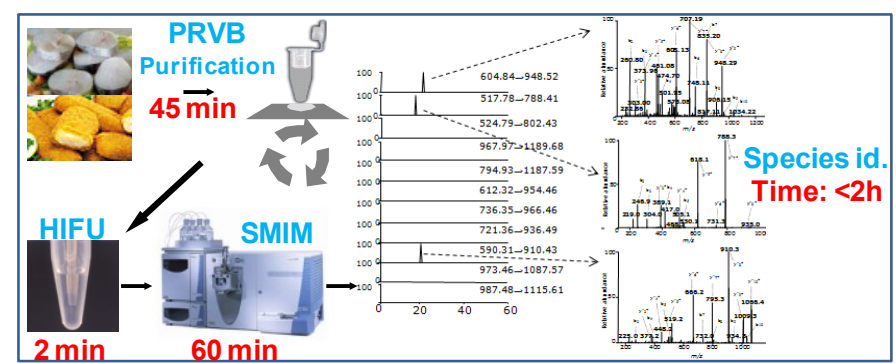

(1) 